\title{
Chapter 25 \\ Funzi Uses the Power of Mobile to Give Everyone Cost-Effective Access to Quality Learning
}

\author{
Aape Pohjavirta
}

Much of what is being discussed and written about in education today is often comes across as complicated and difficult to understand. Yet the task ahead is simple: how to make everyone on the planet learn skills that give them a sustainable livelihood and a happy life without going beyond the available resource limits of our planet. And yet, as simple as the task at hand may seem to be, it is the biggest challenge humanity has ever faced: how to change the behavior of billions of individuals in just a couple of decades if the existing education system during the few thousand years it has existed has not even succeeded in teaching everyone to read?

This article examines some of the causes of the challenges that face us today. It gives examples why existing methods will not help us fast enough, and paints a clear way forward that combines the best sides of existing educational content and systems, and new technologies.

The future can be bright because for the first time in the history of humanity it is possible to give everyone access to quality learning at a fraction of the cost of traditional education. It is possible to give everyone access to the life of their dreams. This article is a true story about a better, happy tomorrow for our planet. And you, dear reader, are the main character in that story, because your actions will decide if we reach Agenda 2030 or not.

\footnotetext{
A. Pohjavirta $(\varangle)$

Funzi, Espoo, Finland

e-mail: aape@funzi.fi

B. Panth and R. Maclean (eds.), Anticipating and Preparing for Emerging Skills and Jobs, Education in the Asia-Pacific Region: Issues, Concerns and Prospects 55, https://doi.org/10.1007/978-981-15-7018-6_25
} 


\section{How Do We Teach for a World that Never Has Been?}

Today's education systems were born to serve the needs of the societies, traditions, and rulers in which they are located. In the past, the part of the population that was educated was small, and the primary task was to transmit skills and knowledge to the next generation, making certain that nothing was "lost in translation." Different types of education systems were developed. The religions developed their own methods to educate their servants in dedicated locations such as monasteries; craftsmen in Europe developed a mentor-apprenticeship model, managed by guilds, that enabled the standardized training of more professional craftsmen to serve the needs of the growing population in the cities. However, the majority of the population remained completely uneducated. The Industrial Revolution changed that.

To be able to take advantage of the full potential of the enormous economic growth enabled by the Industrial Revolution, a new component was required: trained humans. The machines that fueled the growth of economies everywhere had to be operated by humans who could read and understand instructions. The solution for that was to build factories for education: an education system that reached as large a part of the population as possible and delivered to them the skills required to lead their daily lives, operate machines, and follow rules. While the majority of the learners exiting the education system served only a certain purpose such as operating a machine, those who were more capable received a higher level of education, becoming responsible for not only maintaining but also developing the system.

The global education system of today, with its Programme for International Student Assessment (PISA) tests and Ivy League universities, is as good as such an education system will ever become. It is like "Magnificent Mallard," the fastest steam locomotive in the world-impressive and wonderful, but it belongs to the past. The ubiquity of digital software and mobile technologies have created a new set of rules, a new world order that is unlike anything we have seen before. To equip humanity with the skills needed to succeed in that new world requires a total transformation of the education system.

\section{What is Transformation? and How Fast Is It?}

Transformation is one of the many buzzwords we are so used to seeing everywhere that we oftentimes forget what it actually means. I mean, it is easy to say that the global education system must be transformed and then sit down and wait for something to happen. But what does "transformation" actually mean?

According to the Oxford Dictionary of Biology (and I choose this meaning as it must be the closest because education must be a living object and not a fixed mathematical function), it means: "A metamorphosis during the life cycle of an animal," with metamorphosis being "A change of the form or nature of a thing or person into a completely different one." 
So now we know that we have about 15 years to create a completely different education system. ${ }^{1}$

\section{The Power of Digital Technology}

Most of the industries in the world have undergone a transformation during the last few decades. That new world order, driven by digital software, automation, and mobile technologies, has changed how the world works. Old structures have been forgotten, and new, better ones have emerged. The new world is obeying the mantra of "don't make things better, make better things."

Digitalization had a global impact since the late 1980s. The music industry may be taken as an example (CDs, DVDs, iPods), and finally, streaming services changed the consumer-facing part of the industry. And digitalization also had a great impact on the processes within the industry. So, digitalization was driven by both consumers and the industry itself: Everything became more efficient and enjoyable, the quality became higher, and music became more accessible. Digital was good for everyone! First, step by step, the production of music became $100 \%$ digital. Then the playlists that the radio stations used were created, distributed, and delivered digitally. Then came iPods, Spotify, and finally today, in 2019, practically the whole music industry is digital.

The same applies to the movie industry. And, all other types of media: television, radio, newspapers - everything is digital. In all of these industries, digitalization has been driven by both the industry players as well as consumers.

\section{The Weakness of Digital Approaches in Education}

The annual global spending on education is more than six trillion dollars. That is an insane amount of money. And the craziest thing about that money is how little is spent on (i) Transformation and (ii) Digital. Industries that are undergoing a transformation typically spend $10-15 \%$ of their expenditure on research and development in order to remain competitive. The education sector does not. Nor does it invest heavily in digital. And why is that?

One of the biggest reasons for the low level of digitalization in education is the lack of private sector activities and initiatives. The digital development in other industries was accelerated, and in many cases driven, by global industry players who created their own technologies privately while jointly creating technical standards with their competitors. The education industry does not have such global drivers, because no

\footnotetext{
${ }^{1}$ The author used the duration of a learner's studies from start to finish as the life cycle of an animal: $\sim 15$ years.
} 
global players exist in the industry. Even the biggest players are regional players. And that is not big enough to drive a global transformation.

\section{The Mobile Revolution}

The fastest and most impactful of all digital revolutions has been the mobile revolution - starting in the 1980s with the first portable devices, becoming digital in the 1990s, and then becoming a platform for services - first with SMS, then WAP, MMS, mobile apps, and finally the mobile Internet. Today mobile $i s$ the Internet. Tomorrow everything will be mobile.

One of the primary drivers of the mobile revolution is trust. You trust your device. You trust the services you use. Science shows that if you do not trust a service you do not use it. Period. Science also shows that your behavior on your mobile, your trusted device, is driven by the 16 basic desires Steven Reiss identified. This means that, in order for a user to use and continue using mobile services, the services need to address the intrinsic motivation of the users.

Mobile games and music services are great examples of mobile services that have succeeded in attracting users and created completely new behavioral patterns: Once you start using Spotify, going back to listening only to the records you have bought in the past sounds like a stupid idea-as stupid as for a city to choose steam locomotives as their primary method of public transport.

\section{The Future of Learning is in Your Pocket}

Many of the technologies that led to the mobile revolution were invented in Finland, where respect for education and learning is deeply embedded in Finnish society (Ruohotie and Maclean 2006). That is part of the background to why a few years ago a group of mobile industry veterans founded a company to develop a mobile service that would give everyone with mobile device access to quality learning.

The group's goal was to create a service that is proven to produce good learning outcomes among all learner types with any kind of content. And that service would have to work on all connected devices, not only new smartphones but also low tech. And the service would need to be scalable enough to serve the whole world.

That is what Funzi is today. It is a mobile service that combines a pedagogy proven to deliver great learning outcomes with a technology that runs on billions of mobile devices smoothly, even on slow networks, without installing any apps. 


\section{Yes, It Does Work}

In the fifteenth century, after the invention of the printing press, the newly emerged printing industry spent all of its energy for decades doing one thing only: printing artifacts called incunables, only to prove to the world that the new technology could produce exactly the same kind of artifacts as craftsmen already did manually. It took more than 50 years for the world to understand that the strength of the printing press was in the things that craftsmen could not do.

Mobile learning as a term was coined by Alan Kay in the late 1960s. In 1999, John Traxler became the world's first professor of mobile learning, and in the past few decades, thousands of small-scale pilots and projects have been realized. They are the incunables of mobile learning, created to prove that mobile can produce the same results as traditional education.

But for the global education industry to transform itself over the next 15 years, that is not what the world needs; the world needs something better, new. The way the world learns needs to be reinvented. And that is what Funzi does.

The typical reaction to Funzi's claims of impact and scalability is a shake of the head. Industry experts and decision-makers simply do not believe that this could be true. They have yet to comprehend that mobile does everything the classic media does, and much more-not just in communication, music, or games but also in learning.

Mobile enables us, humans, to learn whatever we want, wherever and whenever we want. Mobile enables our learning to merge with the context, to become important for ourselves and our societies. Mobile gives the wings of our minds. Mobile learning gives everyone an equal opportunity to learn. It is the greatest equalizer in the history of humanity. And it is our last chance to maintain humane life on our planet, to reach the Sustainable Development Goals (SDGs) before it is too late.

I dare to state this because we can prove that Funzi works. It is loved by its users and it produces good sustainable learning outcomes. We do not want to make empty claims, and that is why we have validated our claim with multiple data sets.

The easy method to verify this is by looking at the usage patterns of the service. The great retention numbers show that users love the service and come back: More than $58 \%$ of active users return even in the second month. The average length of the sessions-almost 12 min-proves that the users actually study, and finally, the net promoter score from our feedback is $>90$.

In addition to data analysis we conduct active user research: The feedback for Funzi services typically lies between very good and excellent. And to put this all into a globally valid perspective, an academic entity has researched the impact of Funzi (by the United Nations Development Programme in Syria) using the Kirkpatrick model, wherein the answers clearly indicate that respondents found the courses relevant and applicable, expectations were clear, and they have already started seeing positive results from taking the course.

The respondents' answers also indicate that the course was very convenient for them to take on mobile, and more than half the respondents indicated that taking the courses positively impacted mission accomplishment and their personal confidence. 
Only $4 \%$ of respondents in Course 1 and $<2 \%$ in Course 2 believed that they would not be able to apply what they learned.

These results from a crisis- and war-torn Syria prove that Funzi mobile learning is not an incunable. It is a service with the potential to transform how the world learns - today.

\section{Practical Examples}

\section{Case 1: Viet Nam}

In Viet Nam, we are currently working with an education and training company from a leading Vietnamese conglomerate that has many subsidiary companies focusing on real estate development, retail, and services ranging from healthcare to education.

Our customer was looking for an effective digital learning solution to deliver science, technology, engineering, and mathematics (STEM) and entrepreneurship education to high school students. With the aim of reaching 500,000 students by 2020, traditional education methods would be costly and time-consuming. Mobile is an integral part of our everyday lives, and thus an excellent channel for learning. With Funzi mobile learning service, teachers can be certain that the students have learned the content, monitor their progress in real time, use an online reporting dashboard, as well as easily identify the topics students find most challenging to go through in more depth in class. Funzi also works as an online "library" that students can refer to, and access time and time again.

The initial pilot round is targeting 800 high school students from the top 20 schools around Viet Nam. The courses were launched in early March 2019 with the goal to help students acquire the skills they need to tackle pressing environmental challenges.

\section{Case 2: Uganda}

The program on entrepreneurship training for women in information and communications technology (ICT) is sponsored by the Netherlands Trust Fund IV (NTF IV) Uganda. It is implemented by the International Trade Centre (ITC) with the aim of creating a supportive environment for tech start-ups and enterprises in Uganda. ITC has coordinated the implementation and operation of the program hand-in-hand with its partner on-site, Zimba Women, an association aiming at empowering Ugandan women through technology.

Finding new and innovative tools for hubs training women entrepreneurs in Uganda and elsewhere in Africa, specifically women in ICT, is a major challenge. The project utilized the Funzi Founder $101 \mathrm{Hub}$, a blended learning program that consists of participants studying a mobile course and attending on-site sessions facilitated by Zimba Women. During the 6-week program, each week participants studied one-course module as mobile learning, after which they attended an on-site training session that deepened the learning. Through practical tasks and activities, the onsite 
sessions took participants further in improving their own business ideas or their already existing businesses. The program focused on building entrepreneurial skills and a growth mindset in order to be a successful entrepreneur.

Seventy-one percent of those who started the online course completed the program. The results and participant feedback show that blended learning is convenient and effective: a mobile course and on-site sessions are a great combination for bite-sized learning and the practical application of entrepreneurial skills and development of a growth mindset. The on-site component also provides support and peer learning, as well as strengthening participants' networks. Of the participants completing the program, $76 \%$ gave feedback, $74 \%$ of questionnaire respondents considered that the program absolutely made them better equipped to start or grow their business, and an additional $16 \%$ considered it likely.

\section{Case 3: Iraq}

The Funzi Founder 101 course has been used in Iraq to promote entrepreneurship as a career choice. The use of mobiles and mobile technologies can drive the creation of entrepreneurial opportunities and a culture of innovation. Between June 2016 and June 2017, about 3.5 million Iraqis became aware of the Funzi Founder 101. About 350,000 visited the Funzi service and about 40,000 Iraqis became active Funzi learners (of whom roughly $50 \%$ were female).

\section{Conclusion}

There is no doubt that technological developments have transformed the world, and the way in which people learn, work, and utilize their leisure time. Coupled with the characteristics of the Fourth Industrial Revolution, technological developments have resulted in a paradigm shift in human societies. This is true for all societies and economies regardless of whether they are developed, developing, or in transition.

However, regrettably, education and schooling systems have generally lagged well behind in adequately harnessing the new information and communication technologies. This is a matter of concern that needs to be corrected in order to help improve the quality, relevance, and geographical reach of teaching and learning.

Funzi, a company from Finland, provides an excellent role model for other private sector companies as to how good learning access and outcomes can be achieved for anyone who has access to mobile devices.

Links to the presentation materials: https://events.development.asia/materials/ 20171214/technology-and-elearning. https://events.development.asia/materials/201 71214/funzi-mobile-learning-everyone. https://events.development.asia/materials/ 20171214/funzi-mobile-learning-everyone. 


\section{Reference}

Ruohotie, P., \& Maclean, R. (Eds.). (2006). Communication and Learning in the Multicultural World. Finland: University of Tampere and OKKA Foundation Helsinki.

The views expressed in this Chapter are those of the authors and do not necessarily reflect the views and policies of the Asian Development Bank (ADB) or its Board of Governors or the governments they represent.

ADB does not guarantee the accuracy of the data included in this Chapter and accepts no responsibility for any consequence of their use. The mention of specific companies or products of manufacturers does not imply that they are endorsed or recommended by ADB in preference to others of a similar nature that are not mentioned.

By making any designation of or reference to a particular territory or geographic area, or by using the term "country" in this Chapter, ADB does not intend to make any judgments as to the legal or other status of any territory or area.

This work is available under the Creative Commons Attribution 3.0 IGO license (CC BY 3.0 IGO) https://creativecommons.org/licenses/by/3.0/igo/. By using the content of this Chapter, you agree to be bound by the terms of this license. For attribution, translations, adaptations, and permissions, please read the provisions and terms of use at https://www.adb.org/terms-use\#openac cess.

This CC license does not apply to non-ADB copyright materials in this Chapter. If the material is attributed to another source, please contact the copyright owner or publisher of that source for permission to reproduce it. ADB cannot be held liable for any claims that arise as a result of your use of the material.

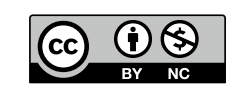

